\title{
Developing Clinical Practice Skills for Pharmacists
}

Galt K A. American Society of Health-System Pharmacists, Bethesda, Maryland, 2006. Softcover, 278 pages. ISBN 978-158528-085-8. US\$68 (US\$61 for ASHP members).

In the preface to this book, the author asks, "What is it about your patient care services as a pharmacist that makes you valuable to society?" This question forms the core of this

$$
\text { JCPH - Vol. 62, n' 3-mai-juin } 2009
$$


useful new reference text, which is suitable for students, new practitioners, and experienced pharmacists.

Developing Clinical Practice Skills for Pharmacists is a well-written, well-organized, and relevant reference for most pharmacists in practice today. Readers will quickly find that much of the book simply does not apply to Canadian pharmacists (and will also quickly feel grateful for living in a country with a universal health care system!). Still, reading this material provides useful insights into how our health care system differs from that of the United States and into some of the unique strengths of the Canadian approach to health, wellness, and practitioner-patient interactions.

The great strength of this book lies in its practical orientation toward patient care. The suggestions related to gathering drug information and evidence, designing patient care plans, and developing strategies to optimize the patient-pharmacist encounter will be familiar to pharmacists, but the approach taken by the author and the practical ways in which she suggests adapting practice to improve patient care are refreshing and relevant.

The author takes pains to ensure that she is discussing generic pharmacy practice skills, and not hospital- or communityspecific practices. This is particularly helpful in Chapter 8 ("Application of Clinical Reasoning"). Even experienced pharmacists who have spent many years working in interprofessional settings will find this chapter helpful.

Throughout the book, there are many useful (and some not-so-useful) features. The use of simulated patient-pharmacist dialogues as a way of illustrating key principles is helpful, offering pharmacists ideas for specific words, phrases, or approaches that they can take to enhancing patient care. A series of general assessment questions appears at the end of each chapter, but these are not as useful, since most of them are somewhat mundane reflective exercises that do not contribute meaningfully to the reader's learning.

This book is probably most applicable to senior-level pharmacy students and new practitioners or to experienced pharmacists who have not had the opportunity to work within a truly collaborative patient-centred practice setting. For these individuals, the skills-based approach emphasized by the author may help in developing a more effective pharmacy practice. Practitioners who are more experienced in patient care may find some of the material redundant or repetitive and thus might benefit from simply cherry-picking through the table of contents. For example, chapters related to the patient record and design of a patient care plan may provide fresh insights and ideas for those already accustomed to documentation and the development of care plans.

Overall, Developing Clinical Practice Skills for Pharmacists would be a useful addition to most pharmacists' libraries. It is an interesting and well-written reference, with the added dividend of providing useful patient-care strategies for novices and experts alike.

Zubin Austin, BScPhm, MBA, MISc, PhD

Leslie Dan Faculty of Pharmacy

University of Toronto

Toronto, Ontario

\begin{tabular}{|c|c|c|}
\hline & Ad Page & Prescribing Information \\
\hline Boehringer-Ingelheim / Pradax & 188 & $256-259$ \\
\hline Hospira / Rocuronium & 184 & - \\
\hline Hospira / Surface Safe & IBC & - \\
\hline The Medi-Dose Group / Corporate & 187 & - \\
\hline Pfizer / Fragmin & 191 & $260-264$ \\
\hline Pharmaceutical Partners of Canada / Corporate & IFC & - \\
\hline Pharmaceutical Partners of Canada / Corporate & $\mathrm{OBC}$ & - \\
\hline Sandoz / Corporate & 182 & - \\
\hline
\end{tabular}

